\title{
Characterizing sand ripples at equilibrium phases
}

\author{
Jie Qin ${ }^{1,2}$, Deyu Zhong ${ }^{2}$, Guangqian Wang ${ }^{2}$ \\ ${ }^{1}$ College of Harbour, Coastal and Offshore Engineering, Hohai University, Nanjing, China. \\ ${ }^{2}$ State Key Laboratory of Hydroscience and Engineering, Tsinghua University, Beijing, China. \\ *Corresponding author. E-mail: qinjie@alumni.cuhk.net
}

\begin{abstract}
Morphological characteristics of ripples are analyzed considering bed surfaces as two dimensional random fields of bed elevations. Two equilibrium phases are analyzed with respect to successive development of ripples based on digital elevation models. The key findings relate to the shape of the two dimensional second-order structure functions and multiscaling behavior revealed by higher-order structure functions. Our results suggest that (1) the two dimensional second-order structure functions can be used to differentiate the two equilibrium phases of ripples; and (2) in contrast to the elevational time series of ripples that exhibit significant multiscaling behavior, the DEMs of ripples at both equilibrium phases do not exhibit multiscaling behavior.
\end{abstract}

Keywords: DEMs; Equilibrium phases; Multiscaling; Wave spectra.

\section{INTRODUCTION}

Identifying and quantifying the characteristics of sand waves is fundamental to the analyses of topography of river bed and its interrelations with flow and sediment transport (Ramsankaran et al., 2010; Rao and Kumar, 2009; Talukdar et al., 2012). Despite significant efforts over last decades, it is still difficult to give assured answers to basic questions such as how to characterize a dune-covered bed, including bedform shapes, sizes, three-dimensionality, and their statistical natures (ASCE, 2002).

Coleman (2011) provided an excellent review related to the historical progression of observations and measurements of sand bed morphology. The first important method for the measurement is the ultrasonic depth-sounder which serves to revolutionize the measurement and analysis of dynamic subaqueous bed topography and introduces landmark advances in understanding and description of bedforms (Coleman, 2011). By this useful tool, one dimensional time series of bed elevation can be easily obtained, from which bedform types, shapes, dimensions, and migration and transport rates have been studied (Jain and Kennedy, 1974; Nikora and Goring, 2000; Nikora et al., 1997). The bed elevation data, however, are one dimensional, so that most research are restricted to investigate the temporal variation of elevation at one or several points. This one dimensional data cannot reflect the spatial variation of the bed topography; on the other hand, three dimensional (3D) pattern of sand waves has been widely reported (Ashley, 1990; Catano-Lopera et al., 2009). The 3D characteristics of sand waves have significant meanings for studying the mechanism of sediment transport. For example, sand waves exhibiting $3 \mathrm{D}$ patterns can potentially increase or decrease form drag on the flow compared with equivalent two dimensional (2D) sand waves in similar flows (Coleman and Nikora, 2011). To characterize the 3D variation of the sand waves, analysis should be conducted based on highprecision digital elevation models (DEMs) directly. Significant advances have beed achieved in recent years based on the highprecision DEMs. By using a 3D-photogrammetric system, Aberle et al. (2012) tested a theoretically-based methodology for the determination of bed load transport and Coleman and Nikora (2011) investigated the causes of highly-ordered sediment waves and important characteristics of a dune-covered sand bed.
Apart from the limitation of one dimensional data, there remains a real need to determine agreed reliable methodologies for estimating bedform characteristics (ASCE, 2002). Even for the visually seemingly straightforward bedform trains of sand waves, it can be difficult to quantify representative bedform characteristics from measured bed profiles (Coleman and $\mathrm{Ni}$ kora, 2011).

Two approaches are currently used in studying sand waves: the discrete and continuous approaches. The discrete approach represents the sand waves as a set of discrete units characterized by height, length, steepness, etc. The continuous approach views the sand waves as a random field of bed elevations $Z(x, y, t)$ where $x$ and $y$ are the longitudinal (streamwise direction) and transverse coordinates, and $t$ is time (Nikora and Goring, 2000). Between these two approaches the first one is the most popular among hydraulic engineers, although the second one may provide important additional information unattainable within the first approach. As natural bed forms are invariably $3 \mathrm{D}$ in alluvial, estuarine and marine environments, the morphological simplification of sand waves has imposed inherent limitations on the interpretation and understanding of dune form and flow dynamics (Parsons et al., 2005). Since the random field approach is more appropriate in studying sand waves than the discrete approach, moment functions such as correlations, spectra and structure functions have been widely used to study the characteristics of river beds (Aberle and Nikora, 2006; Butler et al., 2001; Nikora and Walsh, 2004; Nikora et al., 1998; Smart et al., 2002).

Ripples is the name given to small triangular sand waves formed in the bed (Engelund and Fredsøe, 1982). The bedform development of ripples shows a conspicuous two-phase behavior at flow velocity less than $0.49 \mathrm{~m} \mathrm{~s}^{-1}$, while when velocity larger than $0.49 \mathrm{~m} \mathrm{~s}^{-1}$, time interval between these two phases decreases results in a convergence of the two development phases (Baas, 1999). In the first phase, ripple height and length increase along an exponential path reaching intermediate equilibrium values around $15 \mathrm{~mm}$ and $125 \mathrm{~mm}$, respectively. After some time, a second phase commences that involves a rapid increase in bed-form size, ripple height and length, to the typical equilibrium values around $17 \mathrm{~mm}$ and $140 \mathrm{~mm}$, respectively. Although Baas (1999) used terms such as 'larger size' and 'local linguoid' to characterize the geomorphological features of the second equilibrium phase, there is no simple and reliable 
method to directly differentiate these two equilibrium phases based on the morphological characteristics.

In this paper, we use the random field approach to characterize the morphological development of ripples and to differentiate the two equilibrium phases based on high precision DEMs in (1) two dimensional characteristics of ripples and (2) highorder moments of the elevation field of ripples.

\section{CONCEPTS}

Second-order structure functions (SSFs) is a common approach used to investigate the scaling behavior of river beds (Butler et al., 2001; Nikora et al., 1998; Qin and Ng, 2011; Qin et al., 2012). For a surface exhibiting scaling behavior, the structure functions follow a power law. Therefore when presented in a loglog plot it should follow a power law. In general, the scaling behavior may depend on the lag orientation, and two dimensional structure functions can be employed to investigate the influence of the orientation on the scaling behavior. The generalized two dimensional second-order structure functions (2DSSFs) are estimated from

$$
\begin{aligned}
& D_{G 2}\left(1_{x}, 1_{y}\right)=\left\langle|\Delta Z(1)|^{2}\right\rangle= \\
& =\frac{\sum_{i=1}^{N-n} \sum_{j=1}^{M-m}\left\{\left|Z\left(x_{i}+n \delta x, y_{j}+m \delta y\right)-Z\left(x_{i}, y_{j}\right)\right|\right\}^{2}}{(N-n)(M-m)},
\end{aligned}
$$

where $<>$ means averaging operation, $Z$ is elevation, $l_{x}=n \delta x, l_{y}$ $=m \delta y, \delta x$ and $\delta y$ are the sampling intervals, and $N$ and $M$ are the total numbers of measuring points of bed elevations in direction $x$ and $y$, respectively (Nikora and Walsh, 2004).

The SSFs characterize the mean value of the elevation field, while for surfaces exhibiting multiscaling behavior, higherorder structure functions analysis should be conducted (Gagnon et al., 2006; Singh et al., 2009; Tchiguirinskaia et al., 2000). The scaling behavior of higher-order structure functions DGp(1) may be expressed as

$$
D_{G p}(1)=\left\langle|\Delta Z(1)|^{p}\right\rangle \infty 1^{\xi p}
$$

where $\xi_{p}$ is scaling exponent, with $\xi_{p}=p H(p)$ for simple scaling and $\xi \neq p H(p)$ for multiscaling, $p$ is the order of moments, $H(q)$ is the Hurst exponent.

\section{DATA COLLECTION}

The laboratory experiments were carried out in a $20 \mathrm{~m}$ long, $5 \mathrm{~m}$ wide and $0.50 \mathrm{~m}$ high flume in the State Key Laboratory of Hydroscience and Engineering at the Tsinghua University, China. A schematic diagram of the flume experiment was shown in Fig. 1. The flume was covered with a $0.20 \mathrm{~m}$ thick sand layer, with sand density of $2.65 \mathrm{~g} \mathrm{~cm}^{-3}$. An open channel was then dug along the centerline of the flume with trapezoidal cross section with top width of $0.50 \mathrm{~m}$, bottom width of $0.30 \mathrm{~m}$ and high of $0.10 \mathrm{~m}$. The median grain size was $0.3 \mathrm{~mm}$ and the cumulative size distribution of the sand was shown in Fig. 2. Flow depth was around $0.10 \mathrm{~m}$ and mean velocity was $0.36 \mathrm{~m}$ $\mathrm{s}^{-1}$. The topography of sand waves were measured four time at $8,36,72$ and 144 hours during the experiments when the flow discharge was gradually decreased to zero. The measured beds denoted as surfaces (A), (B), (C) and (D), respectively. The bed topography were measured along the $1.2 \mathrm{~m}$ long test section over a width of $0.20 \mathrm{~m}$ using a photogrammetry approach (Lane et al., 2000). Stereo-photographs were acquired using two single-lens reflex cameras (Nikon D7000), supported on a specially designed movable gantry. The cameras were mounted $1.8 \mathrm{~m}$ above the bed and separated by $0.30 \mathrm{~m}$, with a base: distance ratio of approximately $1: 6$, which met general precision requirements. Three exposure stations were used for each surface which provided a coverage of a $1.0 \mathrm{~m}$ strip of exposed flume bed. The approximate focal lengths of the cameras were 35 $\mathrm{mm}$. The interior parameters were calibrated before the experiment, and exterior parameters were determined using selfcalibrating bundle adjustment methods provided by ERDAS LPS 9.0 software. The DEMs were cropped to include only the sand waves at the center area of channels to remove the influence of boundaries. The area of the cropped DEMs was $1.20 \mathrm{~m}$ $\times 0.20 \mathrm{~m}$. The test section was located $10 \mathrm{~m}$ from the inlet of flume so that neither the scour at the inlet section nor the downstream sill influenced the development of the bed topography. The grid size of DEM was $1 \mathrm{~mm} \times 1 \mathrm{~mm}$ with vertical precision of $0.1 \mathrm{~mm}$. In Fig. 3, the DEMs of four surfaces were shown. Surface (A) shows somewhat regular distribution of sand waves, while irregular patterns were evident on remain surfaces.

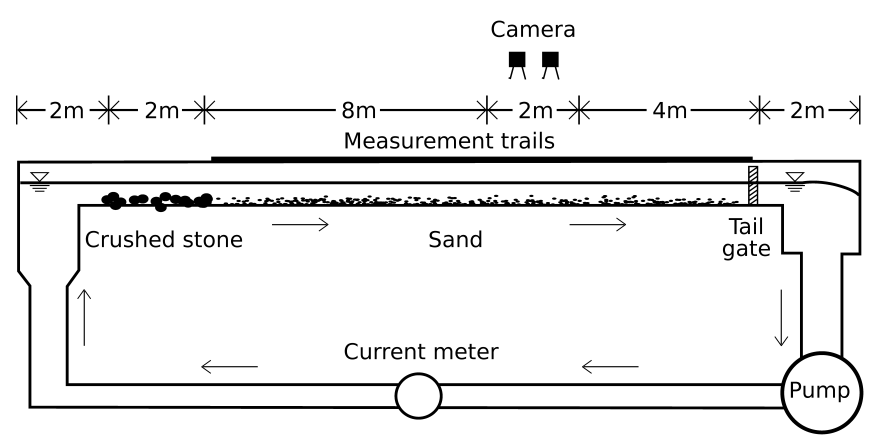

Fig. 1. A schematic diagram of the flume experiment.

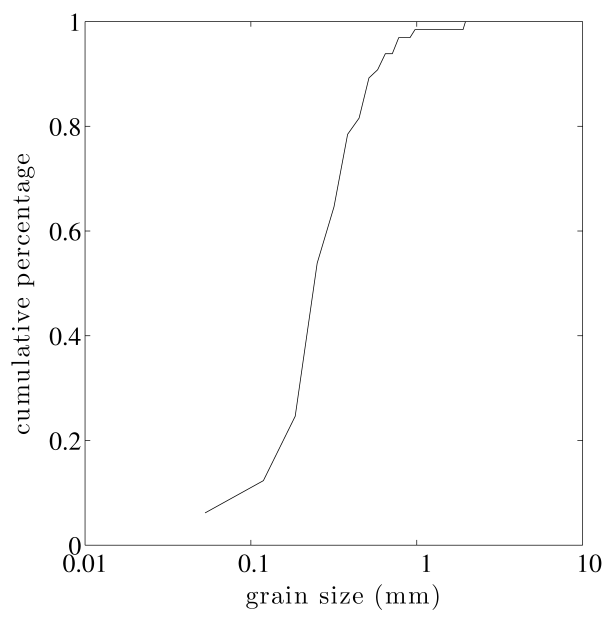

Fig. 2. Cumulative size distribution of the sand used in the experiments. 
(A)

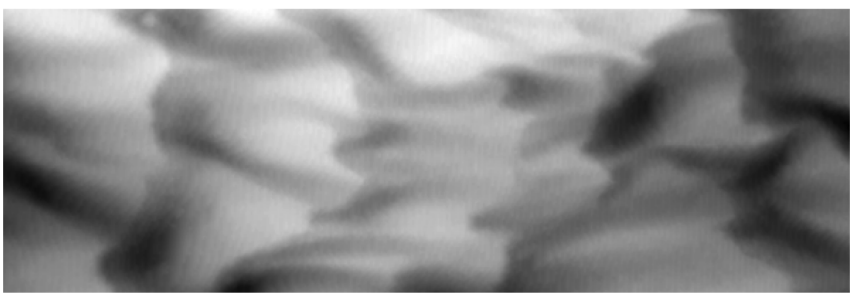

(B)

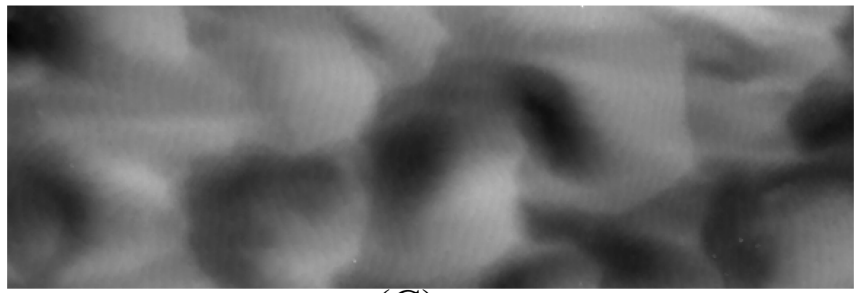

(C)

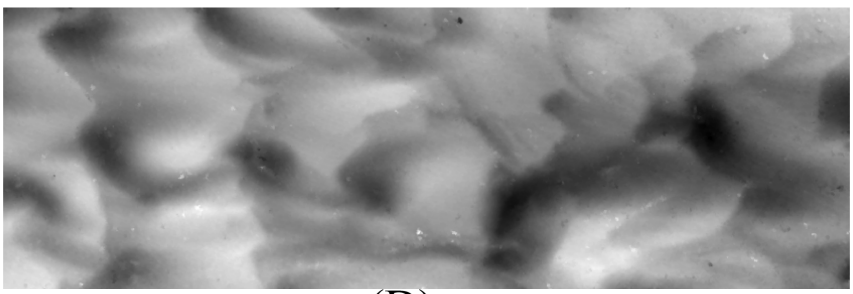

(D)

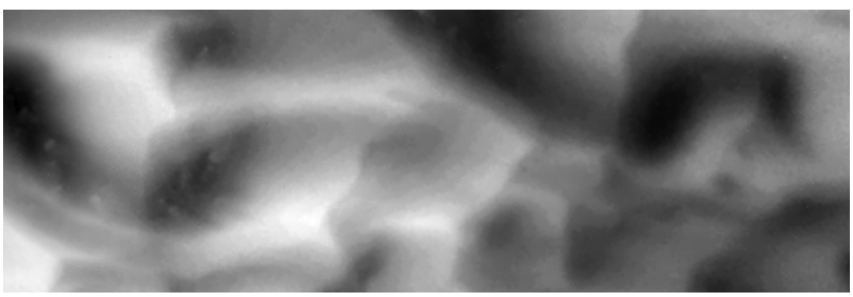

Fig. 3. Digital Elevation Models (DEMs) of sand waves surfaces. Flow direction is from left to right.

\section{RESULTS}

\section{Stage of development of ripples}

If the flow velocity is sufficient to move the individual sediment particles, an initially flat bed is spontaneously deformed into trains of somewhat irregular features called ripples (Kennedy, 1969). The distinguishing characteristics of these bed forms are their shape, longitudinal section being approximately triangular, and their size, the individual ripples generally being less than $0.3 \mathrm{~m}$ in length and $0.03 \mathrm{~m}$ in height (Chien and Wan, 1999). In this study, bedform height and length were measured from the DEMs directly. Mean heights were $0.006 \mathrm{~m}, 0.015 \mathrm{~m}$, $0.018 \mathrm{~m}$, and $0.021 \mathrm{~m}$, and mean length were $0.128 \mathrm{~m}, 0.139 \mathrm{~m}$, $0.147 \mathrm{~m}$, and $0.158 \mathrm{~m}$ for surfaces $(\mathrm{A}),(\mathrm{B}),(\mathrm{C})$, and $(\mathrm{D})$ respectively, which are accordant with the size range of ripples. Another differentiation method of bedforms is proposed by Coleman et al. (2011), who presents a schematic SkewnessKurtosis plane to aid the interpretation of the structure of steady state and developing alluvial bed surfaces from measured bedelevation distributions. The absolute value of the skewness and kurtosis of the elevation field are smaller than 0.3 and 0.5 , respectively, which conforms to the criteria of ripples (Coleman et al., 2011). However, the two equilibrium phases of ripples are hard to be distinguished by the measurement of geomorphological characteristics of ripples. The empirical equation proposed by Baas (1999) based on the equilibrium time are used to differentiate these two equilibrium phases. The equilibrium time for the first phase, $T_{e, 1}$, and the second phase, $T_{e, 2}$, are $5.6 \mathrm{~h}$ and $28 \mathrm{~h}$, respectively. As a consequence, surface (A) corresponds to the first phase of development, while surfaces (B, C and D) to the second phase. For both phases, the ripple crest lines become discontinuous and linguoid ripples are formed, while the equilibrium ripples are larger in size and have local sinuous crest lines as shown in Fig. 3.

\section{Wave spectra and second-order structure functions}

Wave spectra of sand wave surfaces are shown in Fig. 4, in which the ' -3 ' law proposed by Hino (1968) is also depicted. The wave spectra of all surfaces are consistent with the ' -3 ' Hino's law, which indicates that all surfaces are fullydeveloped sand waves and reach equilibrium state in the traditional sense (Hino, 1968; Nikora and Goring, 2000). The spectral ' -3 ' law reflects the statistical spatial self-similarity of longitudinal profiles of ripple. However, there is no significant difference between the spectra of these surfaces.

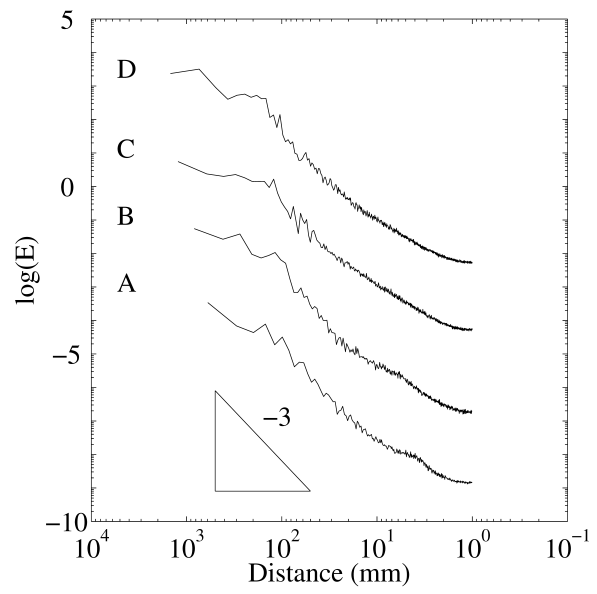

Fig. 4. Wave spectra $\log (\mathrm{E})$ for the sand waves beds. The $\mathrm{x}$ axis is transformed into the actual distance with unit of $\mathrm{mm}$, rather than wave number. Also indicated is the ' -3 ' scaling law proposed by Hino (1968). The wave spectra are shifted vertically for clarity.

Fig. 5 shows the 2DSSFs of the ripples, in which the values are normalized by the variance of the surfaces. Certain contours, $D_{G 2}=0.5,0.7$ and 0.9, are labeled for comparison. Several features can be identified from this figure. First, all surfaces show both isotropic and anisotropic ranges. The isotropic and anisotropic ranges correspond to circles and ellipses on the 2DSSFs, respectively. The isotropic range, characterized by large Hurst exponent (dense circles at the center of 2DSSFs), corresponds to the smooth surface of ripples, while the anisotropic range characterizes the irregular distribution of ripples. Since surfaces (B, C and D) correspond to the second equilibrium phase, the size of ripples on these surfaces are larger than the ripples on surface (A), which is reflected by the increasing isotropic range for surfaces $(\mathrm{B}, \mathrm{C}$ and $\mathrm{D})$. Second, the direction with the strongest correlation, the direction of the long axis of ellipses, is not always along the streamwise direction. Surfaces (B) and (D) show counter-clockwise and clockwise rotation of the ellipse largest axis relative to the streamwise, respectively. Third, the correlation length along with the direction with the strongest correlation increases significantly from the first phase (surface (A)) to the second phase (surfaces (B, C and D)) that contours with $D_{G 2}=0.9$ even cannot be enclosed in Fig. 5 . 
Finally, the short axis perpendicular to the developing direction shrinks significantly from the first phase to the second phase.

(A)

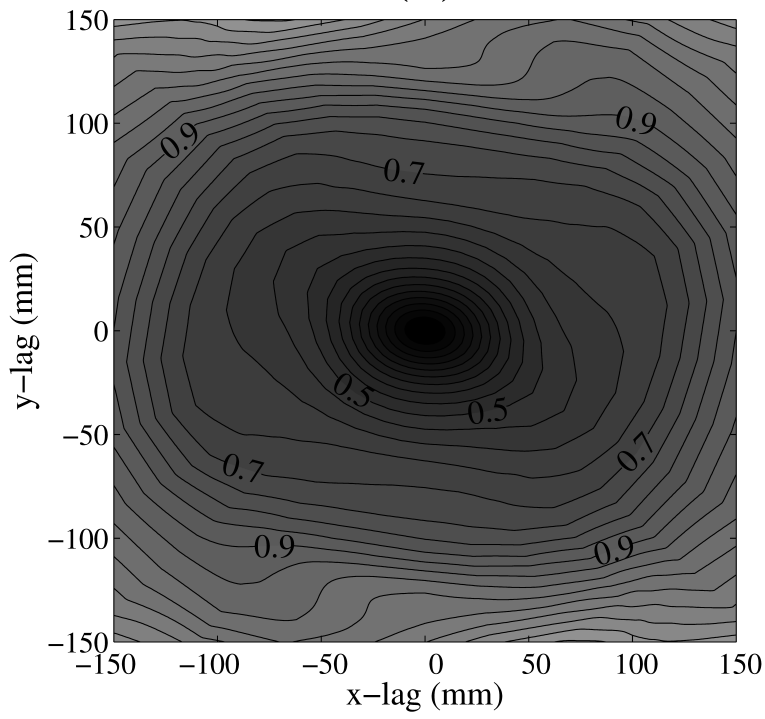

(B)

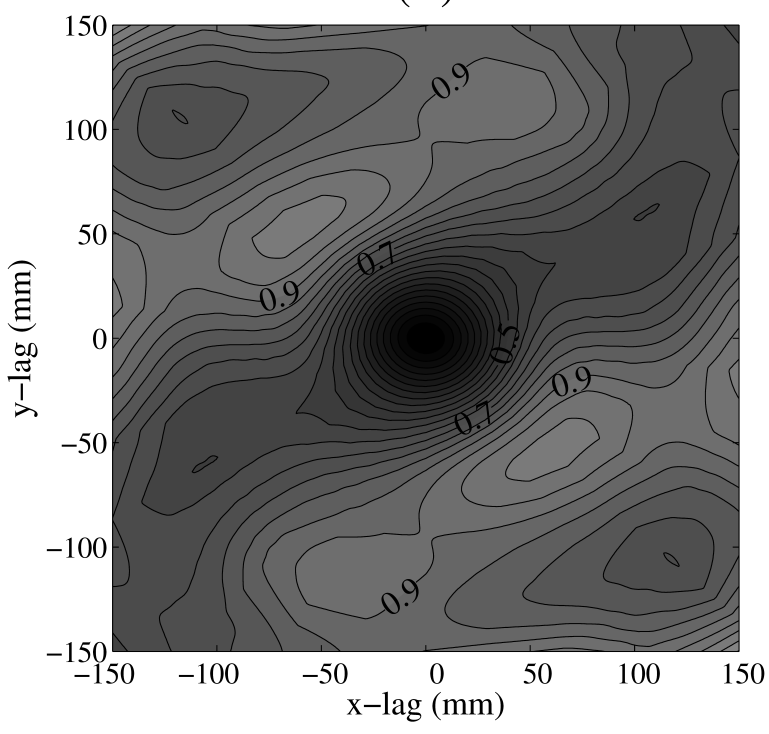

(C)

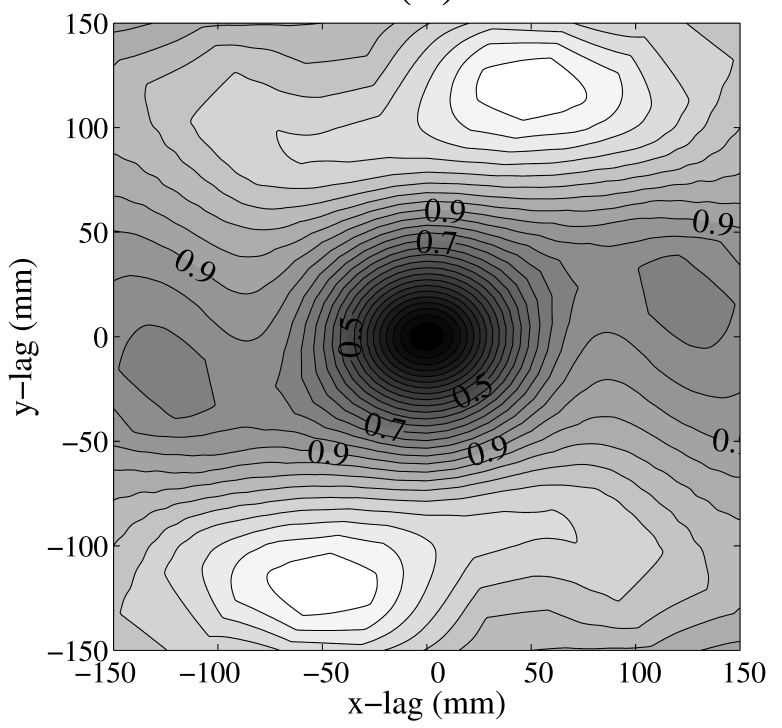

(D)

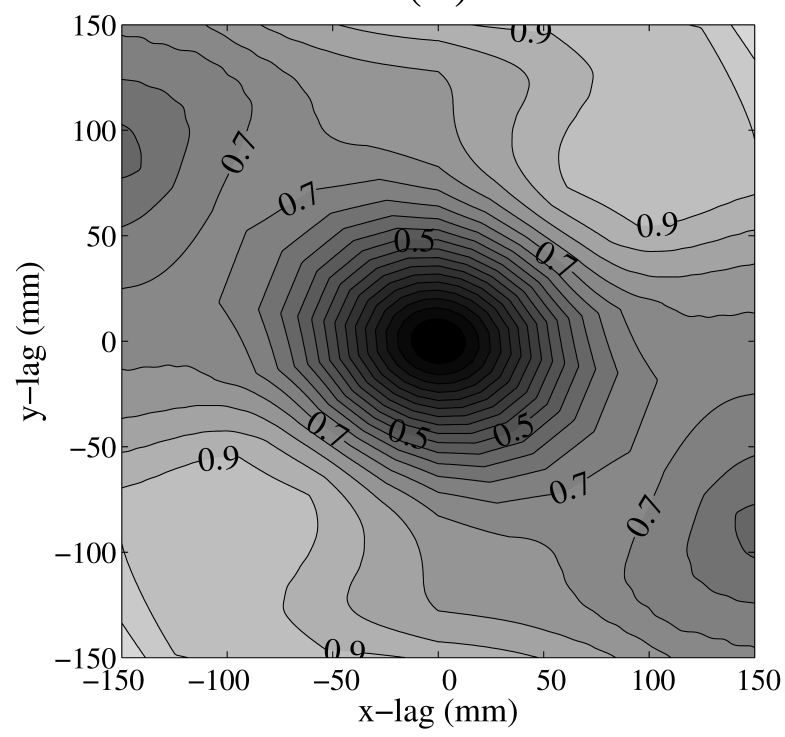

Fig. 5. Contour plots of the 2D second-order structure functions for sand waves surface. All contour lines are normalized with by the variance of the surfaces to enable a direct comparison of the plots. Contours with value of $0.5,0.7$ and 0.9 are labeled. Flow direction is from left to right.

\section{Higher order structure functions}

Fig. 6 shows the generalized structure functions of bed elevations of surface (A) for $q$ from 1 to 10 . At small $q$ the structure functions are fairly well approximated by straight lines that indicate the existence of scaling behavior. The best fit scaling exponents evaluated from the higher-order structure functions are shown in Fig. 7. The trend of the fitted exponents does not significantly deviate from a linear trend for all surfaces, which precludes the existence of multiscaling for the ripple surfaces.

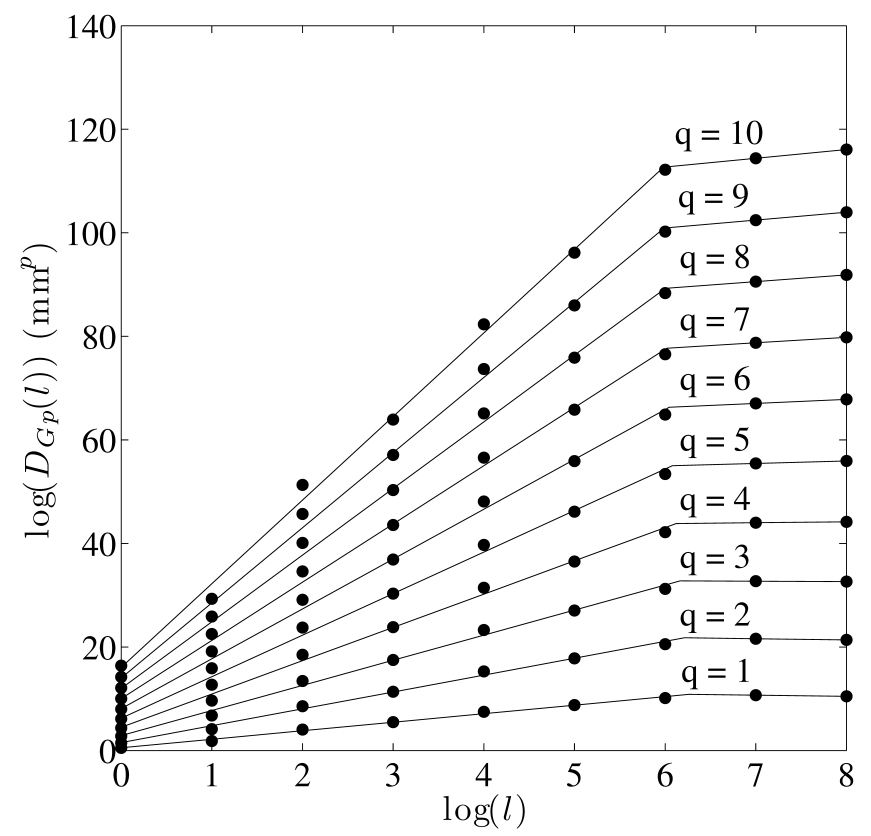

Fig. 6. Generalized structure function of bed elevations $\mathrm{D}_{G p}(1)$ for surface (A). 


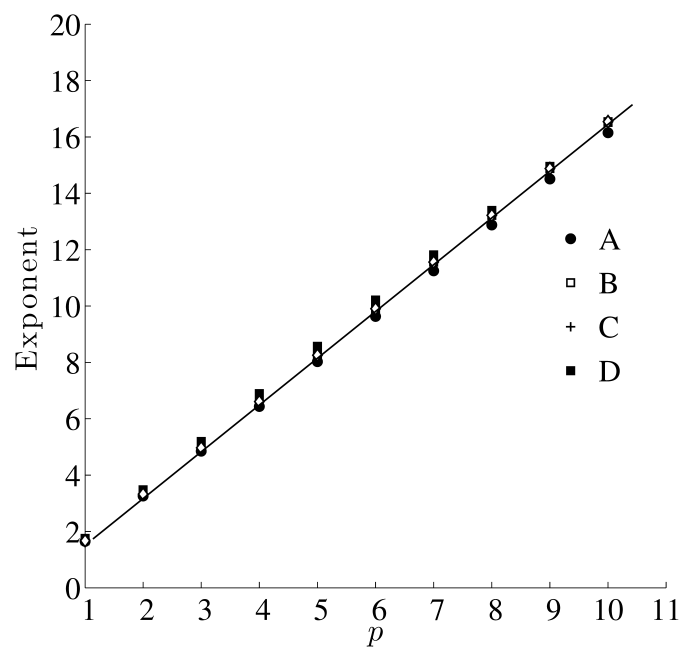

Fig. 7. Fitted exponent $\xi(\mathrm{p})$ from the generalized structure functions. The trend of the fitted exponent does not significantly deviate from a linear trend for all surfaces, which precludes the existence of multiscaling for the ripple surfaces.

\section{DISCUSSION}

Baas (1999) depicted four stages of morphological development and a two-phase equilibrium model for the development of ripples. However, the differentiation of the two phases is difficult for both the observation of the topography and the measurement of ripples. Although Baas (1999) used 'larger size' and 'local linguoid' to characterize the second equilibrium phase of ripple morphology, there is no simple and reliable method to directly differentiate these two equilibrium phases based on the morphological characteristics. In this paper, we use the 2DSSFs to characterize the development of ripples and properly differentiate these two equilibrium phases. The second equilibrium phase has following characteristics: (1) increasing isotropic range due to the increasing size of ripples; (2) correlation length along with the direction with the strongest correlation increasing significantly; and (3) correlation length perpendicular to the direction with the strongest correlation decreases significantly due to the broken of crest lines of ripples. The first and third features of the 2DSSFs correspond to the 'larger size' and 'local linguoid' described by Baas (1999). The possible reason for the second feature may lie in the developing direction of ripples, the dominant direction of moving sand. Because of the morphological continuity along the movement of sand, the correlation length is expected to be larger along the direction of moving sand, the developing direction. However, reliable explanation of the second feature needs further study. The directions with the strongest correlation in the 2DSSFs of surfaces (B, C and D) are different, which may be attributed to two reasons: dynamic nature of the development of ripples and the erodible boundary in this experiment. However, the developing direction of dune surfaces in (Coleman and Nikora, 2011) formed in fixed boundary deviates from the streamwise direction also, which means that the developing direction of ripples may be inherently different than the flow direction.

Interesting results from the higher-order structure functions (HO-SFs) are derived that precludes the existence of multiscaling behavior of ripples. However, the HO-SFs based on the time series of sand waves demonstrate the existence of multiscaling behavior (Nikora and Goring, 2000; Singh et al., 2011). The flow conditions and sand size in Nikora and Goring
(2000) are close to the conditions in current experiment, and the experimental conditions in Singh et al. (2011) are different from current research significantly with flow depth, flow velocity and median grain size being larger than $1.2 \mathrm{~m}, 0.7 \mathrm{~m} \mathrm{~s}^{-1}$ and $1 \mathrm{~mm}$, respectively. Sand waves in Nikora and Goring (2000) include both ripples and dunes, and Singh et al. (2011) only investigated the characteristics of dunes. The reason that the time series and the elevation field of sand waves (ripples in this study) exhibit different multiscaling behavior lies in the irregularity of spatial pattern and dynamic movement of sand waves. Nikora and Goring (2000) found that for small wavelengths, the sand wave propagation velocity is inversely proportional to the wavelength. For large wavelengths, but still within the scaling range, the propagation velocity does not depend on wavelength. The small sand waves move due to the motion of individual sand particles, while larger sand waves propagate as a result of the motion of the smaller waves on their upstream slopes. Both types of motion result in sand wave movement downstream but with different propagation velocity. Another possible reason may relate to the development direction of ripples during the flow process, as indicated by the 2DSSFs in Fig. 5. As a consequence, the one dimensional time series of bed elevation cannot truly reflect the morphological characteristics of bed profiles that in spite of one dimensional time series of bed elevation showing evident multiscaling behavior, the elevational field does not necessarily to be multiscaling as shown in Fig. 7.

\section{CONCLUSIONS}

In this paper, we applied the random field approach for the analysis of $3 \mathrm{D}$ bed elevation data of ripples. The key findings of the study include: (1) the two dimensional second-order structure functions can be used to differentiate the two equilibrium phases of ripples by three features at the second phase: relatively larger isotropic range, increasing correlation length along developing direction and decreasing correlation length perpendicular to the developing direction; (2) ripples for both the first and the second equilibrium phases do not exhibit multiscaling behavior, which means that lower order statistics are sufficient to describe the morphological characteristics of ripples.

Acknowledgments. This work was made possible by the National Natural Science Foundation of China (No. 51039004), and the National Key Technologies R\&D Program of China (No. 2012BAB05B01) is gratefully acknowledged. We thank the anonymous reviewers for their helpful and constructive comments.

\section{REFERENCES}

Aberle, J., Nikora, V.I., 2006. Statistical properties of armored gravel bed surfaces. Water Resour. Res., 42, doi: 10.1029/2005WR004674.

Aberle, J., Coleman, S.E., Nikora, V.I., 2012. Bed load transport by bed form migration. Acta Geophys., 60, 17201743.

ASCE Task Committee on Flow and Transport over Dunes, 2002. Flow and transport over dunes. J. Hydraul. Eng., ASCE, 128, 726-728.

Ashley, G.M., 1990. Classification of large-scale subaqueous bedforms - a new look at an old problem - sepm bedforms and bedding structures. J. Sediment Petrol., 60, 160-172. 
Baas, J.H., 1999. An empirical model for the development and equilibrium morphology of current ripples in fine sand. Sedimentology, 46, 123-138.

Butler, J.B., Lane, S.N., Chandler, J.H., 2001. Characterization of the structure of river-bed gravels using two-dimensional fractal analysis. Math. Geol., 33, 301-330.

Catano-Lopera, Y.A., Abad, J.D., Garcia, M.H., 2009. Characterization of bedform morphology generated under combined flows and currents using wavelet analysis. Ocean Eng., 36, 617-632.

Chien, N., Wan, Z.H., 1999, Mechanics of Sediment Transport. ASCE Press, Reston, Va.

Coleman, S.E., 2011. Experimental Investigations of Sandy Riverbed Morphology. In: Rowinski, P.M. (Eds): Experimental Methods in Hydraulic Research. Springer, New York, 1-27.

Coleman, S.E., Nikora, V.I., 2011. Fluvial dunes: initiation, characterization, flow structure. Earth Surf. Proc. Land., 36, 39-57.

Coleman, S.E., Nikora, V.I., Aberle, J., 2011. Interpretation of alluvial beds through bed-elevation distribution moments. Water Resour. Res., 47, doi: 10.1029/2011WR010672.

Engelund, F., Fredsèe, J., 1982. Sediment ripples and dunes. Annu. Rev. Fluid Mech., 14, 13-37.

Gagnon, J.S., Lovejoy, S., Schertzer, D., 2006. Multifractal earth topography. Nonlinear Proc. Geoph., 13, 541-570.

Hino, M., 1968. Equilibrium-range spectra of sand waves formed by flowing water. J. Fluid Mech., 34, 565-573.

Jain, S.C., Kennedy, J.F., 1974. The spectral evolution of sedimentary bed forms. J. Fluid Mech., 63, 301-314.

Kennedy, J.F., 1969. The formation of sediment ripples, dunes, and antidunes. Annu. Rev. Fluid Mech., 1, 147-168.

Lane, S.N., James, T.D., Crowell, M.D., 2000. Application of digital photogrammetry to complex topography for geomorphological research. Photogramm. Rec., 16, 793-821.

Nikora, V.I., Goring, D.G., 2000. Sand waves in unidirectional flows: Scaling and intermittency. Phys. Fluids, 12, 703-706.

Nikora, V.I., Walsh, J., 2004. Water-worked gravel surfaces: High-order structure functions at the particle scale. Water Resour. Res., 40, doi: 10.1029/2004WR003346.
Nikora, V.I., Sukhodolov, A., Rowinski, P.M., 1997. Statistical sand wave dynamics in one-directional water flows. J. Fluid Mech., 351, 17-39.

Nikora, V.I., Goring, D.G., Biggs, B.J.F., 1998. On gravel-bed roughness characterization. Water Resour. Res., 34, 517527.

Parsons, D.R., Best, J.L., Orfeo, O., Hardy, R.J., Kostaschuk, R., Lane, S.N., 2005. Morphology and flow fields of threedimensional dunes, Rio Parana, Argentina: Results from simultaneous multibeam echo sounding and acoustic Doppler current profiling. J. Geophys. Res., 110, doi: 10.1029/2004JF000231.

Qin, J., Ng, S.L., 2011. Multifractal characterization of waterworked gravel surfaces. J. Hydraul. Res., 49, 345-351.

Qin, J., Zhong, D., Ng, S.L., Wang, G., 2012. Scaling behavior of gravel surfaces. Math. Geosci., 44, 583-594.

Ramsankaran, R., Maerker, C., Malcherek, A., 2010. Numerical modelling of hydrodynamics and sediment transport processes during storm events in a non-perennial river. J. Hydrol. Hydromech., 58, 36-48.

Rao, A.R., Kumar, B. 2009. Analytical formulation of the correction factor applied in Einstein and Barbarossa equation (1952). J. Hydrol. Hydromech., 57, 40-44.

Singh, A., Lanzoni, S., Foufoula-Georgiou, E., 2009. Nonlinearity and complexity in gravel bed dynamics. Stoch. Env. Res. Risk A., 23, 967-975.

Singh, A., Lanzoni, S., Wilcock, P.R., Foufoula-Georgiou, E., 2011. Multiscale statistical characterization of migrating bed forms in gravel and sand bed rivers. Water Resour. Res., 47, doi: 10.1029/2010WR010122.

Smart, G.M., Duncan, M., Walsh, J., 2002. Relatively rough flow resistance equations. J. Hydraul. Eng., ASCE, 128, 568-578.

Talukdar, S., Kumar, B., Dutta, S., 2012. Predictive capability of bedload equations using flume data. J. Hydrol. Hydromech., 60, 45-56.

Tchiguirinskaia, I., Lu, S., Molz, F.J., Williams, T., 2000. Multifractal versus monofractal analysis of wetland topography. Stoch. Env. Res. Risk A., 14, 8-32.

Received 2 September 2012 Accepted 20 March 2013 